\title{
Troubled Waters: Navigating Unintended Consequences of Health Information Technology
}

\author{
C. U. Lehmann', B. Séroussi' ${ }^{2},{ }^{3}$ M.-C. Jaulent ${ }^{3}$ \\ 'Departments of Biomedical Informatics and Pediatrics, Vanderbilt University Medical Center, \\ Nashville, TN, USA \\ 2 Sorbonne Universités, UPMC Université Paris 06, LIMICS, UMR S 1142 , Paris, France; AP-HP, \\ Hôpital Tenon, Département de Santé Publique, Paris, France \\ 3 INSERM, UMR_S 1142, LIMICS, Paris, France
}

\begin{abstract}
Summary
Objectives: To provide an introduction to the 2016 IMIA

Yearbook of Medical Informatics by the editors.

Methods: We present a brief overview of the 2016 special topic

"Unintended consequences of Health IT: new problems, new

solutions", we review our choice of special topic section editors, and discuss the transitions in the editorial team for next year.

Results: This edition of the Yearbook acknowledges the fact that implementation and use of Health Information Technology (HIT) may result in unintended consequences, which may lead to both adverse and sometimes beneficial outcomes. However to date, in the literature, undesired outcomes are emphasized with a focus on the complex causes and the many sources that may generate them. The growing awareness of the importance of HIT's unintended consequences and their increasing documentation reflect a wider acceptance of HIT by users (more use generating more consequences) and and a new type of users (a shiff from early adopters to late adopters and laggards), whith great expectations regarding the improvement of care quality through HIT solutions. Different points of view on new problems and new solutions of unintended consequences of Health IT are presented through the keynote paper, survey papers, and the working group contributions.

Conclusions: The regular 2016 issue of the IMIA yearbook focuses on new unintended consequences of Health IT - brought on by wider adoption and different types of users as well as solutions to addressing them.
\end{abstract}

\section{Keywords}

Editorial, 2016 IMIA Yearbook of Medical Informatics, Unintended consequences of Health IT, IMIA and its societies

Yearb Med Inform 2016:5-6

http://dx.doi.org/10.15265/IY-2016-056

Published online November 10, 2016
Health information technology (HIT) offers the promise of improving quality of care through the optimization of health information exchange and care coordination, the implementation of state of the art clinical practices, and the reduction of medication errors and adverse events. Electronic health records (EHRs), computerized provider order entry systems (CPOEs), and clinical decision support systems (CDSSs) are among the tools, which can make the delivery of care safer, more effective, and more efficient. The expectations of improved care describe the intended consequences of HIT, which have been observed and reported, especially when the systems are locally developed by the biomedical informatics departments of university hospitals to fit the needs and workflows of their users.

However, recently we have also witnessed some unintended consequences that are potentially harmful for patients and were first described by Ash et al. in their JAMIA paper published in 2004 [1]. They described the introduction of technology-induced errors or "e-iatrogenesis" (as defined by Weiner et al [2]) as "patient harm caused at least in part by the application of health information technology". In 2012, Coiera et al. predicted the advent of a "dangerous decade" in healthcare [3]. With more and more health information technology coming online [4] and with an increasing complexity of systems, new unintended consequences of HIT must be expected and have been observed such as new types of patient safety risks (e.g., wrong patient selection) resulting from many factors like poorly-designed user interface, disrupted workflow, and communication breakdowns. Psychosocial dimensions of HIT must also be taken into account as users engage and become more familiar with HIT and begin to rely more and more on technology to guide them - which in turn may introduce novel errors - both of omission and commission. This overreliance on clinical systems or "automation bias" (as coined by Goddard et al. in [5]) occurs for example when systems do not provide an alert after an incorrect provider action like ordering an inappropriate medication, but users assume that there is no reason to worry about drug-drug or drug-allergy interactions. Alternatively, overreliance can occur when systems provide incorrect alerts but providers follow the recommendation blindly and introduce new errors (like an alert of clopidogrel and acetylsalicylic acid interaction in a post-op cardiac stent patient resulting in the discontinuation of one of the medications).

While the majority of unintended consequences of HIT may cause adverse outcomes, some may be beneficial. For these reasons, the editorial committee of the International Medical Informatics Association (IMIA) Yearbook has chosen to devote the special topic of its 2016 edition to "Unintended Consequences of HIT: new problems, new solutions". Well known and respected authors and experts accepted to contribute to this edition of the Yearbook. The keynote paper was written by four US researchers (Sittig, Wright, Ash, and Singh), who have long been involved in evaluating unintended consequences. Ross Koppel and Yunan Chen guided the review of the literature and the selection of the best papers for the special section. While the Yearbook generally tries to avoid US centric teams, for the topic of 
unintended consequences this expert team was the logical choice because of the state of adoption in the US. The US Health Information Technology for Economic and Clinical Health (HITECH) Act resulted in over \$US 30 Billion being spent on the implementation and use of EHRs. These funds as Doug Fridsma, CEO of the American Medical Informatics Association (AMIA), pointed out resulted in a conversion of $20 \%$ of the largest gross domestic product from paper to electronic in a matter of five years. Subsequently, the US has seen the highest rates of adoption leading to the highest rates of new unintended consequences and increased research into their causes and prevention [6].

The editors' charge to the authors of the special topic was a discussion of novel unintended consequences. While there is still much to report and discuss in respect to unintended consequences discovered in the early days of electronic health records [7], we asked the authors to focus on novel consequences that are driven by the scope of implementation and the different users interacting with HIT systems to date.

In 2016, the Yearbook team delivered not one but two Yearbooks - our 25th anniversary edition as well as the regular Yearbook issue. We have to thank the many authors and contributors, who came through for us delivering their outstanding work sometimes with tight deadlines. Two issues created a significant amount of additional work for the editorial team including our outstanding Editorial Assistant Martina Hutter. However, we are proud of the results and hope that our readers agree.

This Yearbook team managed with the help of the IMIA Board of Directors and our friends at Schattauer Verlag to bring the Yearbook to an Open Access format, which allows informaticians in resource poor parts of the world to use the Yearbook. In addition, with the gracious help of Reinhold Haux, head of the Peter L. Reichertz Institute for Medical Informatics in Braunschweig, Germany, we brought all old issues of the Yearbook online as well.

The yearbook team has been publishing the Yearbook since 2013. However, in the near future, the Yearbook team will be seeing some significant changes. Marie-Christine Jaulent will be leaving the editorial team and Christoph U. Lehmann, who will become President of IMIA in 2017, will vacate the position of Vice President (VP) of Services. Brigitte Séroussi will provide continuity and will advance to the IMIA Board of Directors and become the new Vice President of Services. In turn, two new editors will join the team. John H. Holmes, PhD, FACE, FACMI, who is a Professor of Medical Informatics in Epidemiology, in Biostatistics, and Epidemiology at the Hospital of the University of Pennsylvania, will be joined by Lina F. Soualmia, PhD, who is an Associate Professor at the French University of Rouen, France. We are very sad to announce that Martina Hutter, who has served as the Editorial Assistant since 2000, is planning to leave the Yearbook in 2017 after the team has been able to find a replacement. Martina will be tremendously missed - she has brought great spirit, continuity, and hard work to the Yearbook for 17 years.

Undoubtedly so much change is likely to bring some unintended consequences as well. However, the outgoing editorial team is convinced of the Yearbook's future success and is looking forward to the many new ideas and concepts the new team will develop. We are certain that the Yearbook will be in great hands and we are looking forward to becoming reviewers and possible contributors to future editions. Please help us to welcome the new editorial team!

\section{References}

1. Ash JS, Berg M, Coiera E. Some unintended consequences of information technology in health care: the nature of patient care information system-related errors. J Am Med Inform Assoc 2004 Mar-Apr;11(2):104-12.

2. Weiner JP, Kfuri T, Chan K, Fowles JB. "e-iatrogenesis": the most critical unintended consequence of CPOE and other HIT. J Am Med Inform Assoc 2007;14(3):387-8; discussion 389.

3. Coiera E, Aarts J, Kulikowski C. The dangerous decade. J Am Med Inform Assoc 2012 JanFeb;19(1):2-5.

4. Lehmann CU, O'Connor KG, Shorte VA, Johnson TD. Use of electronic health record systems by office-based pediatricians. Pediatrics 2015 Jan;135(1):e7-15.

5. Goddard K, Roudsari A, Wyatt JC. Automation bias: empirical results assessing influencing factors. Int J Med Inform 2014 May;83(5):36875. doi: 10.1016/j.ijmedinf.2014.01.001. Epub 2014 Jan 17.

6. Slight SP, Berner ES, Galanter W, Huff S, Lambert BL, Lannon C, Lehmann CU, McCourt BJ, McNamara M, Menachemi N, Payne TH, Spooner SA, Schiff GD, Wang TY, Akincigil A, Crystal S, Fortmann SP, Bates DW. Meaningful Use of Electronic Health Records: Experiences From the Field and Future Opportunities. JMIR Med Inform. 2015 Sep 18;3(3):e30. doi: 10.2196/medinform.4457. PubMed PMID: 26385598; PubMed Central PMCID: PMC4704893.

7. Campbell EM, Sittig DF, Ash JS, Guappone KP, Dykstra RH. Types of unintended consequences related to computerized provider order entry. J Am Med Inform Assoc 2006 Sep-Oct;13(5):547-56. 